\title{
Do Diversity and Context Collapse Kill an Online Social Network?
}

Júlia Koltai ${ }^{1,2,+}$, László Lőrincz ${ }^{3,4}$, Johannes Wachs ${ }^{5,6}$, and Károly Takács ${ }^{7,1}$

${ }^{1}$ Centre for Social Sciences, Computational Social Science - Research Center for Educational and Network Studies (CSS - RECENS), 1097 Budapest, Tóth Kálmán u. 4., Hungary, koltai.julia@tk.mta.hu

${ }^{2}$ Eötvös Loránd University of Sciences, Faculty of Social Sciences, Pázmány Péter sétány 1/A., H-1117 Budapest, Hungary

${ }^{3}$ Corvinus University of Budapest, Networks Technology and Innovation Lab, 1093 Budapest, Fövám tér 8., Hungary

${ }^{4}$ Centre for Economic and Regional Studies, Institute of Economics, 1097 Budapest, Tóth Kálmán u. 4., Hungary

${ }^{5}$ Vienna Uni. of Econ. and Business, Welthandelspl. 1, 1020 Vienna, Austria.

${ }^{6}$ Complexity Science Hub Vienna, Josefstädter Straße 39, 1080 Vienna, Austria.

${ }^{7}$ The Institute for Analytical Sociology (IAS), Linköping University, 60174 Norrköping, Sweden.

${ }^{+}$corresponding author

The first two authors contributed equally to this work.

Word count: 7980. 


\section{Do Diversity and Context Collapse Kill an Online Social Network?}

Our social lives are segmented into various circles including family, friends, and colleagues. Differences in social norms and expectations between these circles can create tension, especially on large online social networks (OSNs), where their boundaries are blurred. It is unclear whether such phenomenon, called context collapse, outweighs the convenience of having diverse communities in one place for users of OSNs. To better understand this trade-off, we analyze whether ego-network characteristics suggestive of context collapse can explain exit choices from iWiW, a defunct Hungarian OSN with over 3.5 million active users at its peak. We measured context collapse with the presence of two conditions: the first is that communities of the user are non-overlapping, while the second is that these communities are different from each other. We find that users having merely overlapping communities were more likely to stay on the site. This result suggests that the benefits of being connected to diverse communities outweighs the tension from context collapse. Differences in gender composition of alter communities were associated with leaving, while having geographically distant connections were associated with staying longer on iWiW. Our results suggest that the tradeoff between access to diverse contacts and the stress of context collapse is a salient dimension in predicting user churn.

Keywords: online social networks, diversity, context collapse, ego-networks, social capital, modularity 


\section{Introduction}

People have contact with diverse groups. One's family members, old school friends, colleagues, and neighbours can be very different with regard to their interests, attitudes, or political preferences. In the offline world, these differences rarely conflict as most of the time these groups are not present at the same place and same time. In online social networks (OSNs), however, these groups are not so easily kept apart. Such situations can create tension and stress for individuals, especially when their different social circles have diverse norms and expect them to follow incompatible roles (Binder et al., 2012). This situation is known in the literature as context collapse: when diverse audiences are all present on the same platform (Marwick \& Boyd, 2011; Davis \& Jurgenson, 2014) and evaluate the same social performance of an individual. Offline, individuals would usually adjust their behavior and presentation to the group they are interacting with; online, we cannot make these adjustments so easily. For example, one's social media post can be liked by university friends and acquaintances but meet with disapproval by family members.

Context collapse is known to have a significant effect on behavior online, though its role in the exit of users from specific platforms is understudied. In this paper, we investigate whether context collapse could contribute to the likelihood that a user abandons an online social network (OSN). To start, we identify user ego network indicators which may signal that a user experiences context collapse. The first kind of indicator is based on the extent to which one's connections are segregated into distinct communities. The second kind measures how demographically similar or different these groups are. Then, we study the relationship between these indicators and the likelihood that the user leaves the OSN. We use the anonymized dataset of iWiW (international Who is Who), a once large but now defunct Hungarian OSN. 
Our work builds on previous research into why individuals stay on or leave OSNs. For example, social capital benefits can explain when and whether people abandon an online social network (Lőrincz et al., 2019). Other studies concentrate on the effects of interaction overload and unwanted relationships on leaving (Hwang et al., 2019). Furthermore, recent studies have found that using attributes computed from the local community around the user allows building a robust statistical model to predict churn (Garcia et al., 2013; Lengyel et al., 2020; Ngonmang et al., 2012; Török \& Kertész, 2017). According to our knowledge, this is the first attempt to assess the role of context collapse in the abandonment of an online social network. Hence, our research contributes to the literature of churn processes.

\section{Clashing expectations of diverse groups}

The perspectives we encounter in the different contexts of our lives can be highly diverse. As suggested by Simmel, we live at the intersection of these social circles (Simmel, 1908/2009; Alba \& Kadushin, 1976). New circles are added with new stages of life: starting secondary school or university, changing workplaces, moving to another city, taking up a new hobby, joining a voluntary association, breaking up or divorcing with a partner, or bringing children to kindergartens and schools (Alwin et al., 2018). Our social life is divided between different circles and our ego networks are significantly clustered by these contexts, though the extent of this clustering varies significantly from person to person (Feld, 1981; Fischer, 1977).

Cultural codes, meanings, and values often vary between these groups: opinions and norms that are acceptable in one group can be disliked or condemned in another. Sometimes these groups overlap and intersect; in a traditional village community, neighbors might also be co-workers and relatives. More typically, however, members of the different groups do not meet often, and one can play different roles in these contexts. Individuals avoid conflict between 
incompatible roles and expectations of these circles as these groups are more or less separable from each other. Individuals behave according to the actual role, which meets the expectations of the group they are currently present in (Goffman, 1978).

This natural hypocrisy that eases our lives is more difficult to perform in online social networks. OSNs break down the boundaries between the diverse groups the ego belongs to. When an individual posts content to the social media, contacts from all their different social circles, with their different norms and expectations, can observe it. This context collapse affects our online behavior and activity differently than clearly separable face-to-face audiences do (Marwick \& Boyd, 2011; Vitak, 2012).

Context collapse consists of two core ingredients, both of which must be present. One is to have several distinct groups in the ego-network of the individual. The other is that the composition of these groups has to be different in some way that is salient to the formation of norms and expectations. We measure the presence of the first using the modularity (Newman \& Girvan, 2004) of the ego-network, a measure of the tendency of links to be within rather than between distinct groups of alters. The second one is described by the dissimilarity of the communities. The lack of modularity indicates the absence of distinct groups in a user's social network. If the communities are similar to each other, it is more likely that they share similar norms and social meaning, thus it is also more likely that they have similar expectations towards the individual, which decreases potential tension.

The presence of context collapse in online social networks, its relationship with user behavior, and privacy strategies are widely studied (see e.g. Marwick \& Boyd, 2014) on different platforms like Facebook (Brandtzaeg \& Lüders, 2018; Vitak et al., 2012; Costa, 2018; Beam et al., 2018), Twitter (Marwick \& Boyd, 2011), or YouTube (Wesch, 2009). Context collapse 
creates a kind of stress of self-representation that is stronger in highly diverse networks (Hogan, 2010; Binder et al., 2012). Additionally, context collapse could also be relevant in a temporal dimension in a sense that older content can affect the interactions of the present (Brandtzaeg $\&$ Lüders, 2018). The presence of context collapse can even cause the feeling of a loss of privacy (Marwick \& Boyd, 2014). Others argue that how users use online platforms influence the emergence of context collapse, which can be avoided by proper privacy settings (Costa, 2018).

\section{Strategies for managing context collapse}

For some individuals, context collapse is not a salient issue because their networks are homogeneous. Homogeneity could also evolve over time due to selective attention, which algorithms of social media platforms can also augment. Such dynamics create filter bubbles and echo chambers that pose other kinds of problems for the user like boredom and redundancy (e.g., Flaxman et al., 2016).

In offline contexts with high diversity tensions can arise from conflicting expectations (Milliken \& Martins, 1996). Individuals need to invest in adjustment strategies and efficient diversity management is needed in order to harvest the benefits from diversity while preventing conflict (Jehn, 1995; Pelled et al., 1999).

In online social networks, once tension from context collapse is experienced, it could be suppressed in multiple ways. User may manage their networks by not confirming the friend requests of those, who are not part of their inner circle or create a separate account for these wider audiences (Vitak et al., 2012). Individuals might constrain their self-representation in large and diverse networks (Burkell \& Fortier, 2016), and they could limit the expression of their characteristic opinions and taste. They could also change to observation mode at the OSN without any substantial sharing activity (Hogan, 2010). Alternatively, those who are 
exhibitionists in their characters could decide to broadcast their true opinions without any filtering and sensitivity to their reception in the network (Boyd, 2008). Observers and exhibitionists at the two extremes of activity. Majority of users develop strategies to cope with the tension of diversity by balancing for their diverse audience (Vitak et al., 2015), just like how politicians communicate to a diverse set of voters. And finally, they might resolve the tension by abandoning the OSN.

\section{Social network positions and the utility of OSNs}

In addition to considerations related to context collapse, social network positions of individuals may influence the utility of staying on the online social networks by several mechanisms. Bridging positions are associated with access to diverse and novel information, that entails benefits of brokerage (Burt, 2005). Such positions allow the individual to exchange favours across these groups (Jackson, 2020; Jackson et al., 2012), which may be a benefit for the individual. From the ego's perspective, it means that the user connects distinct groups, which are not connected to each other directly, which is also a form of social capital (Burt, 2005). Being a broker, so in the intersection of otherwise cohesive, but loosely connected groups, can be measured with modularity of ego networks. Thus, modularity can both indicate the presence of context collapse and the broker role of an ego. This presents a dilemma: the stress of context collapse might push a user to leave an OSN, while the social capital benefits of a diverse network offer incentive to stay on the platform.

Another important characteristic of ego-networks is the level interconnection between alters. Being member of an interconnected network may increase the potential for mobilizing and preserving social resources (Lin, 1999), which in online social networks is correlated with engagement and perception of community (bonding social capital) (Brooks et al., 2014; Tian, 
2015). High interconnection is also an indication of strong, high-bandwidth ties (Aral \& Van Alstyne, 2011); having higher frequency and more types of interactions (Granovetter, 1973; Burt, 1995). For users having mostly strong ties, staying on the OSN may be less essential, as they possibly have several further means of communication. Network structure, where individuals are sparsely interconnected, however, is an indication of weak ties, with more selfinterested motivation (Uzzi, 1997). For those who collected many weak ties, communication available by the OSN may be more essential. To control for these mechanisms, we introduce the clustering coefficient to the models, which measures the chance that two of ego's random friends know each other.

Concerning the diversity of ego-networks, on the one hand, having connections to a diverse set of others is associated with higher exposure to a wider range of ideas and stimuli, which can contribute to the individual's social capital (Borgatti et al., 1998). On the other hand, people prefer to interact with those, who are similar to themselves (Lazarsfeld \& Merton, 1954; McPherson et al., 2001), consequently they also discuss important matters with these persons (Mardsen, 1988). Thus, having similar friends may decrease the excitement, but increase the self-assurance from the online social network. To control for this mechanism, we include difference measures between the ego and their alters to the models, in addition to the measures of dissimilarity between the different communities of ego, corresponding to context collapse.

To better understand the balance of these forces, we study the relationship between ego network structure and continued use of iWiW (international Who is Who), a once large but now defunct Hungarian OSN. Early OSNs were primarily used to maintain social ties, and contained much less dynamic content than on platforms that are widely used today. With Facebook having gained worldwide popularity, national and local OSNs could not stand the competition and 
typically shut down between 2008 and 2013 (see Lörincz et al., 2019). The study of an early OSN like iWiW is especially appropriate for our substantive questions, because at that time, users flocked to OSNs without realizing the tensions that they might create. This also holds for the managers of OSNs: they were not yet aware of the potential problem of context collapse and hence technological features that could have decreased its negative impact hardly existed yet.

While users of Facebook can also experience context collapse, we argue that the introduction of Facebook in Hungary offered an escape from an increasingly heterogeneous environment of iWiW. For some time, early adopters of Facebook in Hungary were likely to encounter a more exclusive group of users on the new platform without any tension from context collapse.

\section{Research questions and hypotheses}

Could context collapse be stressful enough to push users to leave an OSN? This is an important problem both from a theoretical perspective as social capital benefits of diversity might counterbalance tension from context collapse, but also from a practical perspective of OSN providers who do their best to tailor their sites to keep their users. Tensions from context collapse are larger if the user has a diverse and fragmented ego-network. Yet social capital benefits are amplified by similar concepts: having many contacts and in key structural positions, for instance, in those that are characterized by structural holes in the ego-network (Burt, 2004; Burt, 2005).

Hence, we formulate hypotheses about the impact of individual ego-network measures on the probability of leaving the OSN. Following Brooks et al. (2014) and Wachs et al. (2019), we used the modularity of ego networks as a measure of their structural diversity. We use the measure to quantify the context collapse in the ego's online experience. High values of modularity indicate that an ego's communities or contexts are distinct and disconnected. 
H1: In accordance with arguments on context collapse, we expect that high modularity of the ego-network increases the likelihood of leaving the OSN.

Potential for context collapse also increases if dissimilarities between communities of the ego are larger in key dimensions of taste, demographics, and geographical proximity. Although differences could occur in several relevant dimensions, we can test the impact of heterogeneity of the ego-network regarding gender, age, and spatial distance in our data.

H2: Based on arguments on context collapse, one can expect that larger differences between the social circles in key dimensions of gender, age, and geographical proximity increase the likelihood of abandoning the OSN.

As we assume that both high modularity and large differences between communities are necessary conditions for context collapse, we assume that the positive interaction of modularity and dissimilarity of communities in one's ego network has positive effect on leaving the OSN.

H3: We hypothesize that the effect of modularity and dissimilarity between communities strengthen each other. In particular, we expect a positive interaction between modularity and the dissimilarities between communities, indicating that the effect of modularity is increased, if dissimilarity is higher.

\section{Materials and Methods}

\section{Data}

We analyze the network and user data of an OSN that has been offline for several years. iWiW was founded in 2002 and was one of the first widespread online social networks in the world. At its peak, with its more than 3.5 million users, it was the biggest OSN in Hungary with a population of 10 million, where this meant two-thirds of all Internet users. After 2010, with the 
appearance of Facebook, iWiW began to lose users. After a decline in user activity, it was shut down by the provider in 2014. We analyze the archived and anonymized database of iWiW provided by its former owners. From the original dataset we deleted users who registered on the site, but never logged in; users with zero connections, and also ones with more than 2000 connections, to exclude celebrities and those with commercial interests. We also excluded users, who reported registration age under 14 . With these criteria we removed $18 \%$ of users. The 3.8 million remaining users were not necessarily active across the full lifecycle of the platform. For computational reasons, we carry out our analyses on a random sample of approximately 10,000 users. Note that the analysis of ego-networks of such a large sample is valid both from the statistical as well as from the substantive point of view to draw conclusions about the entire population. The descriptive statistics of the sample and the entire iWIW data are presented in Table 1. The composition of the sample and the whole iWIW are similar to each other.

For the analysis, we use the interval between January 2007 and December 2012. Less than 1\% of users left the site before 2007 , and only $30 \%$ remained after 2012 , when our observation period ended.

Table 1. Descriptive statistics of users in the sample.

\begin{tabular}{lllllll}
\hline & \multicolumn{3}{c}{ Sample for the analysis } & \multicolumn{3}{c}{ Entire iWIW data } \\
& Mean & SD & N & Mean & SD & N \\
\hline Age & 36.54 & 13.88 & 6,837 & 36.49 & 13.83 & $2,495,067$ \\
Gender & $\begin{array}{l}\text { Male: } \\
45 \%\end{array}$ & $\begin{array}{l}\text { Female: } \\
55 \%\end{array}$ & 10,311 & $\begin{array}{l}\text { Male: } \\
45 \%\end{array}$ & $\begin{array}{l}\text { Female: } \\
55 \%\end{array}$ & $3,762,529$ \\
& & & & & \\
Registration & $08 / \mathrm{Nov} /$ & 534.8 days & 10,311 & $30 /$ Oct/ & 569.5 & $3,762,529$ \\
date & 2007 & & & 2007 & days & \\
$\begin{array}{l}\text { Last login } \\
\text { date }\end{array}$ & $\begin{array}{l}27 / \mathrm{Apr} / \\
2012\end{array}$ & 393.8 days & 10,311 & $\begin{array}{l}22 / \mathrm{Apr} / \\
2012\end{array}$ & $\begin{array}{l}424.7 \\
\text { days }\end{array}$ & $3,762,529$ \\
\hline
\end{tabular}




\section{Data Structure}

To analyze the relationship between context collapse and leaving the network, we consider the monthly snapshots of the ego-networks of each user in our sample throughout the 72 months observation period. Our observations are at the level of user-month, which means that each of the 10,000 users is present in the dataset as many times as many months they spent in the network within the observed period, and their ego-networks are created from the whole database for each month. For example, the first row shows the data of the first user in their first month, the second row shows the data of the same user in the second month, etc. Altogether we have 533,419 observations (rows) in the dataset. The user appears the first time in the dataset in the month they joined the social network and their last appearance is the month when they left the network. For each user, we flag the last month they spent in the network creating the 'leave' variable with the value 1 for the last month of the user, and the value 0 for each preceding month. Characteristics of the users in each month are recorded in different variables (columns). For each user, there are time-invariant variables (e.g., gender) and also time-varying variables (e.g., number of connections). Table 2. illustrate the data structure, where User1 joins the network in January 2007 and stays for four months, while User2 joins in February 2008 and leaves three month later. Additionally, User10,000 joins in January 2008 and stays during the whole period, until December 2012. 
Table 2. Structure of the dataset

\begin{tabular}{|l|l|l|l|l|l|l|l|}
\hline & $\begin{array}{l}\text { Month spent in } \\
\text { the network }\end{array}$ & Date & Leave & Gender & $\begin{array}{l}\text { N of } \\
\text { contact }\end{array}$ & $(\ldots)$ & Modularity \\
\hline User1 & 1 & $2007 \_01$ & 0 & male & 20 & & .21 \\
\hline User1 & 2 & $2007 \_02$ & 0 & male & 32 & & .23 \\
\hline User1 & 3 & $2007 \_03$ & 0 & male & 34 & & .23 \\
\hline User1 & 4 & $2007 \_04$ & 1 & male & 51 & & .25 \\
\hline User2 & 1 & $2008 \_02$ & 0 & female & 12 & & .20 \\
\hline User2 & 2 & $2008 \_03$ & 0 & female & 43 & & .21 \\
\hline User2 & 3 & $2008 \_04$ & 1 & female & 67 & & .25 \\
\hline$(\ldots)$ & & & & & & & \\
\hline User10,000 & 1 & $2008 \_01$ & 0 & female & 21 & & .21 \\
\hline User10,000 & 2 & $2008 \_02$ & 0 & female & 45 & & .23 \\
\hline User10,000 & 3 & $2008 \_03$ & 0 & female & 55 & & .23 \\
\hline$(\ldots)$ & & & & & & & \\
\hline User10,000 & 72 & $2012 \_12$ & 1 & female & 233 & & .32 \\
\hline
\end{tabular}

\section{Measures}

Our binary dependent variable is leaving the site in a given month. We use the label 'leaving the site' for the time when the last login occurred. The average probability of leaving the network in a random month was 1.3 percent. Its high standard deviation (11.3\%) is due to the increased likelihood of leaving in 2012 (Figure 1).

Figure 1: Probability of leaving by month in the analysis

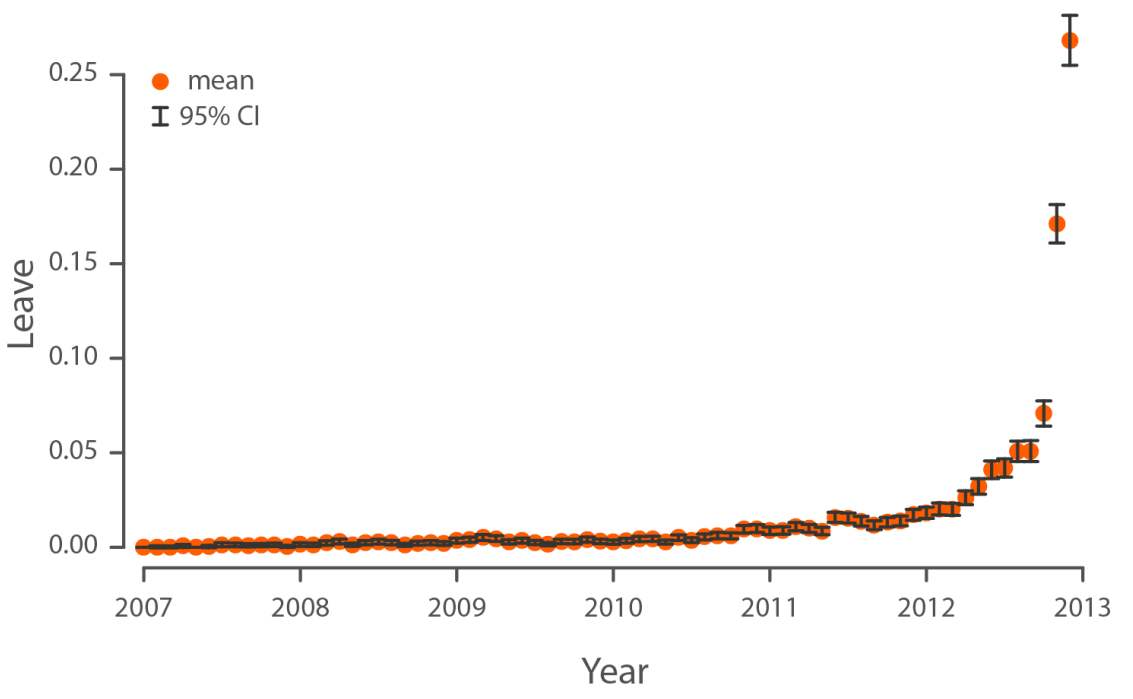


We use modularity as one measurement for the potential of context collapse, thus we test H1 by estimating the relationship between modularity of the ego-network on leaving the OSN using a regression model. To quantify modularity of an ego network, we first used the Louvain community detection algorithm (Blondel et al., 2008) to obtain a mutually exclusive classification of individuals in the ego-network for each month. We then measure the extent to which edges are within these groups of alters rather than between them. (For more detailed description of this measure see Appendix A1.) We calculated a modularity score (in the [-1,1] interval, though typically between $[0,1]$ ) for each individual and each month (for the 533,419 observations), indicating how distinct identified communities are in the sense of having high network density within, and low density between them. Because high modularity indicates that a user's friends belong to non-overlapping communities, it can increase the emergence of context collapse for ego.

We measure demographic dissimilarities between different communities corresponding to $\mathrm{H} 2$ in three dimensions. We consider self-reported user variables of gender (a mandatory user field, hardcoded on iWiW as "male" and "female"), age, and location as dimensions for this measure. 
Figure 2. Examples of four ego-networks with different modularity (panel A and B) and dissimilarity (panel C and D) are illustrated on Figure 2. Panel A shows an ego-network with low modularity, while network B's modularity is high, representing the first and the third quartiles of the modularity distribution, respectively. Panel C and D show two networks with around the same value of modularity, but with different levels of gender dissimilarity between communities. Panel C shows an ego network, where the communities are heterogenous from the gender perspective, while panel D visualize a network, where different communities have different gender compositions.

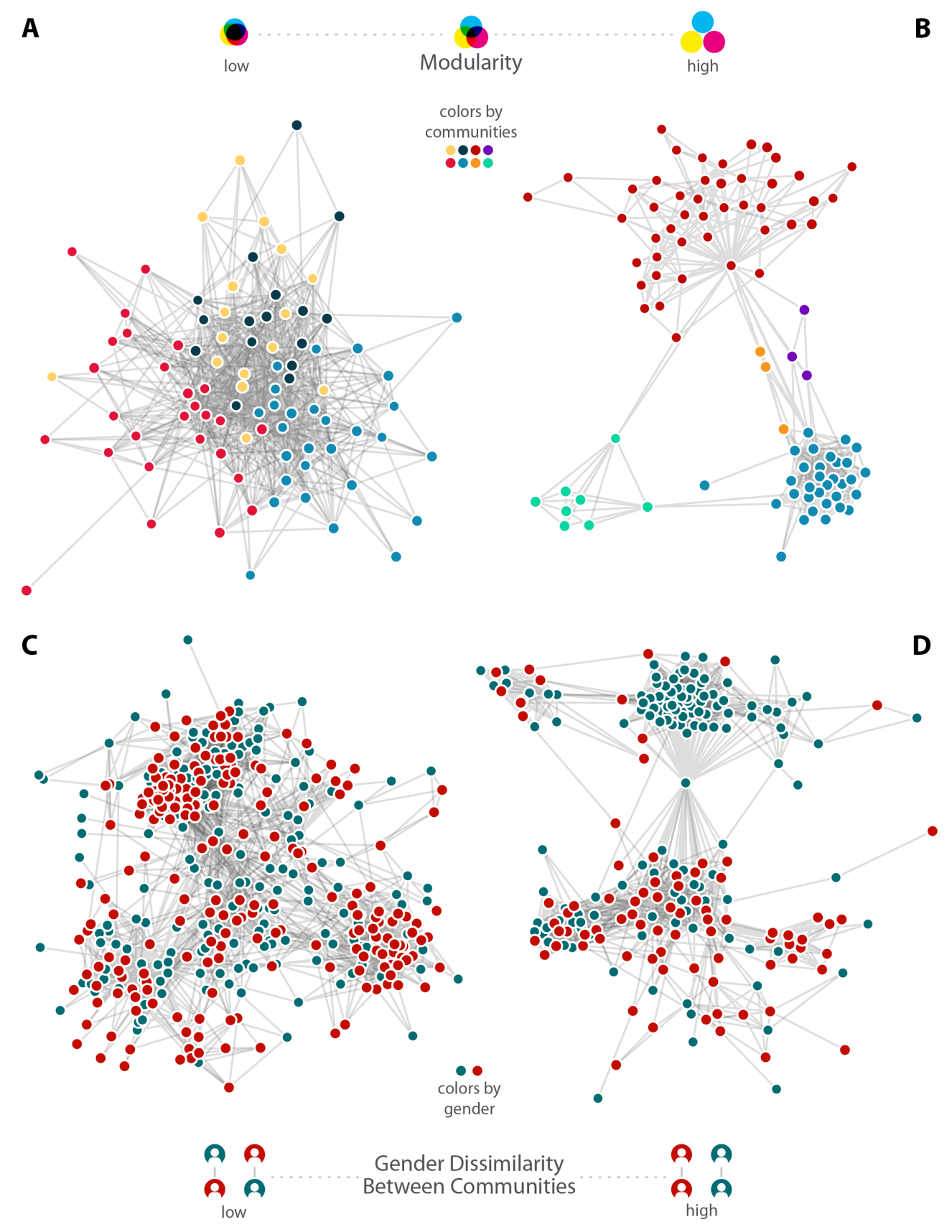


To obtain the dissimilarities, we first calculate the average values of each communities of a user, then take the differences between the community averages. As users usually have more than two communities, we aggregate these dissimilarities pairwise (cf. e.g., Kossinets \& Watts, 2009). Given a pair of communities, we first record their sizes, noting that the contribution of any two communities to a measure of dissimilarity between all communities of an ego must consider that larger communities likely play a more important role in creating contexts for the ego. For each pair of alter communities we then calculate the absolute differences in their values. We multiply each of these differences by the product of the sizes of the two communities, and sum the result over all pairs of communities. Finally, to scale the result so that it is comparable for ego networks of different sizes, we divide by the sum of the products of the sizes of all pairs of communities:

$$
\text { age dissimilarity }=\sum_{k=1}^{K} \sum_{l=1}^{K} \frac{N_{k} N_{l} \mid \text { avg_age }_{k}-\text { avg_age }_{l} \mid}{\sum_{k=1}^{K} \sum_{l=1}^{K} N_{k} N_{l}} \text {, for each } k \neq l,
$$

where $N_{k}$ and $N_{l}$ represents the sizes of kth and lth communities, K shows the number of communities and avg_age denotes the average age of individuals in the given community. Therefore, our community age dissimilarity measure corresponds to the expected difference of the average age between two randomly selected communities of the ego, if the communities are selected proportionally to their sizes.

Community gender dissimilarity corresponds to the expected difference between the share of women between two random communities, if the communities are selected proportionally to their sizes. Thus, the calculation is similar to the one of age dissimilarity if we substitute the average age with the share of women within the community. It has a zero value, if 
all communities have the same gender composition, and one if ego has two communities, one of which is a male-only and the second is female-only.

For geographic distance, we consider the average distance across all pairs of nodes in each pair of communities, then take the average of this distance across all pairs of communities, weighted by the sum of their sizes.

$$
\text { geographical dissimilarity }=\sum_{i=1}^{N_{k}} \sum_{j=1}^{N_{l}} \frac{d_{i, j}}{\sum_{k=1}^{K} \sum_{l=1}^{K} N_{k} N_{l}}, \text { for each } i \in k, j \in l, k \neq l \text {, }
$$

where $\mathrm{d}$ is the geographic distance in kilometers between the residence of person $\mathrm{i}$ and person $\mathrm{j}$ who belong to different communities of k and 1; $N_{k}$ and $N_{l}$ represent the sizes of kth and lth communities and $\mathrm{K}$ is the number of communities. Thus, community distance dissimilarity corresponds to the expected geographic distance in kilometers between two alters, who belong to different communities. Note that the formula is similar to the age dissimilarity with changing the difference of average ages with the average geographical distance of each pairs of nodes of the two communities.

To control for the dissimilarity between the ego and their friends, we calculated the average dissimilarity of ego and his or her contacts from the perspective of age, gender and location. To avoid confusing these with the above measures of community dissimilarities, we will use the term "distinction" for these ones. In the case of age distinction of ego from his or her communities, we used

$$
\text { age distinction }=\sum_{k=1}^{K} \frac{N_{k} \mid \text { age }_{\text {ego }}-\text { avg_age }_{k} \mid}{\sum_{k=1}^{K} N_{k}}
$$

where ${ }^{K}$ represents the number of communities, $N_{k}$ shows the size of kth community, avg_age denotes the average age of the given community; and ageego is the age of ego. Thus, high age 
distinction refers to high difference between ego and the average age of their communities. Gender distinction is calculated similarly, but instead of average age, we use the share of women within the communities. The value of gender distinction is zero, if all members of all communities have the same gender as ego, and one, if ego only has communities with members of different gender than he or she is.

With regard to the geographic distance of ego and his or her friends, we calculated

$$
\text { geographical distinction }=\sum_{i=1}^{N} \frac{d_{\text {ego }, i}}{N}
$$

where $\mathrm{d}$ is the geographic distance in kilometers between the residence of the ego and his or her alter i, and ${ }^{N}$ represents the number of ego's alters. Thus, geographical distinction shows the average geographical distance between ego and his or her alters.

To summarize, we have three types of measures describing ego networks. First, modularity is a structural measure that describes the distinctiveness and separation of communities in the ego network of a user, corresponding to H1. Second, community dissimilarity describes distances between the ego's communities in terms of gender, age, and geographical location, corresponding to H2. Third, we use the ego's distinction to describe the distances between the ego and their communities in terms of gender, age, and geographical location, as control variables. Each measure offers a qualitatively different perspective of ego's potential contextual diversities. Means and standard deviations of these key variables are shown in Table 3. We observe some missing values across the variables, which causes some variations in the number of observations. 
Table 3. Descriptive statistics of the main and control variables of the hypothesis

\begin{tabular}{llll}
\hline & Mean & SD & N \\
\hline Leave & 0.0129 & 0.113 & 533,419 \\
Modularity & 0.34 & 0.15 & 532,658
\end{tabular}

Community dissimilarity

$\begin{array}{llll}\text { Age } & 5.85 & 3.78 & 521,306 \\ \text { Distance (100 kms) } & 0.655 & 0.425 & 525,113 \\ \text { Gender } & 0.17 & 0.09 & 525,144\end{array}$

Ego's distinction

$\begin{array}{llll}\text { Age } & 8.44 & 4.48 & 378,194 \\ \text { Distance (100 kms) } & 0.444 & 0.411 & 532,643 \\ \text { Gender } & 0.41 & 0.14 & 532,654\end{array}$

Network control variables

\begin{tabular}{llll}
$\mathrm{N}$ of connections & 213.40 & 183.65 & 533,419 \\
$\mathrm{~N}$ of communities & 4.43 & 1.55 & 532,658 \\
Clustering (local) & 0.16 & 0.13 & 530,431 \\
\hline
\end{tabular}

\section{Statistical methodology}

To predict leaving the OSN, we use discrete-time survival models (Allison, 2014). We choose a non-parametric baseline hazard function as we do not have a priori assumptions about its form, and because our main research interest lies in the regression parameters, namely in the interpretation of the effects of the independent variables on leaving (Cox, 1972). Independent variables include both time-invariant and time-varying variables. The first group of independent variables include characteristics of the users, namely age and gender. The second group of 
independent variables are related to the users' connections and contain the number of connections they have, the number of different communities (detected by Louvain community detection), the modularity score, and the local clustering coefficient. The third group of independent variables is built up by the above-described community dissimilarity measures according to age, location and gender. The fourth group of independent variables we include in the models are the ones, which measure the distinction of ego from the ego-network communities, from the perspective of age, location and gender. Statistical calculations were executed by STATA's logit and margins commands.

\section{Results}

\section{Two-way analysis}

Qualitatively, we observe that the higher the modularity of an individual's ego-network is, the less likely that he or she would leave the OSN (Figure $3 \mathrm{~A}$ ). This is the opposite pattern compared to our expectation $\mathrm{H} 1$, as it suggested that a greater separation between the communities of an ego predicts that an ego will leave sooner. At the same time, we observe small raw differences in the likelihood of leaving with regard to the community dissimilarities of the ego-networks (expressed in $\mathrm{H} 2$ ).

In order to put our hypotheses to a rigorous test, we use discrete-time survival models. The following section presents our baseline model with regard to $\mathrm{H} 1$ and $\mathrm{H} 2$. We extend the model with interactions to test $\mathrm{H} 3$ subsequently. 
Figure 3. The likelihood of leaving by modularity and community dissimilarity
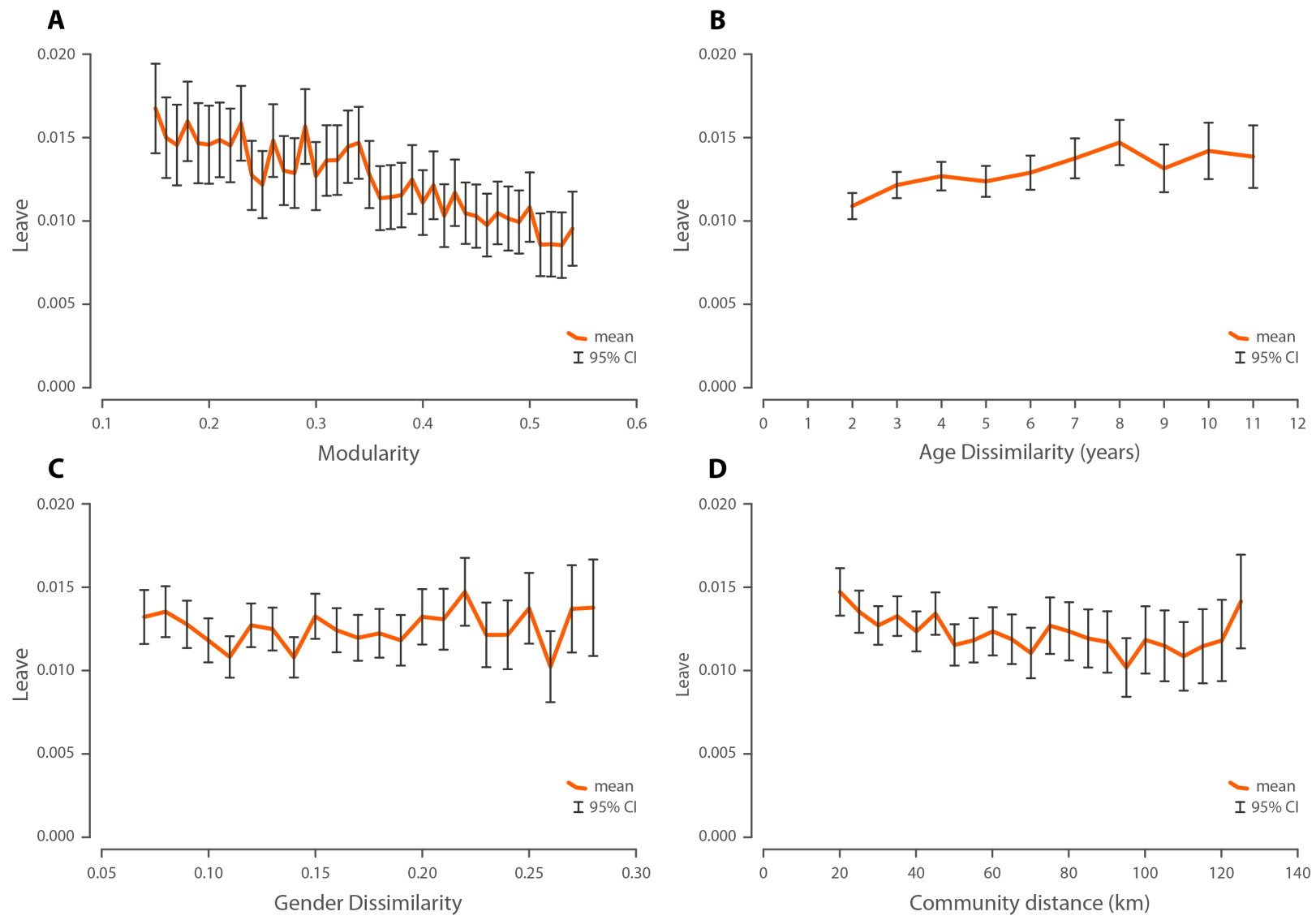

\section{Baseline model}

We analyze the impact of context collapse indicators in a stepwise manner. First, we consider modularity (Table 4 Model 1). Second, we enter the community dissimilarity measures without modularity (Model 2). Third, we consider the community dissimilarity measures jointly with modularity (Model 3). Finally, we add control measures of ego's distinction from his or her network (Model 4) to the model. Throughout the analysis, we control for observable user (age, gender) and ego-network (number of friends, number of communities, and clustering) characteristics.

Table 4 shows the main results. The effect of modularity is negative in each model, indicating that more separated, less interlocking communities prevent users leaving the site, in 
contrast to what we expected based on context collapse (H1). Geographic distance between communities also has a negative effect on leaving in Models 2 and 3, so both with and without controlling for modularity. When we control for ego's distinction from his or her network (Model 4), however, this effect disappears. Hence, it is actually the spatial distance between ego and his or her network that is associated with staying on the site longer. The coefficients of gender and age dissimilarities between communities display the opposite tendency. The more dissimilar one's communities are from the perspective of gender and age, the more likely that the individual will leave. These effects are positive and significant both in Models 2 and 3, so the inclusion of modularity does not influence these results. In the last model, where we control for ego's distinction from his or her network, the effect of age dissimilarity disappears, but the effect of gender composition differences between different circles remains significant. Model 4 also shows that a large age difference between the ego and his or her network increases the chance to leave. Hence, we find support for $\mathrm{H} 2$ about the impact of context collapse on leaving the site in the demographic dimensions, but not in the dimension of spatial differences. In particular, users seem to be disturbed by having communities with different kinds of gender imbalance at the same time.

Our user-level controls show that older users tend to stay longer on the site in contrast to younger users. We can also see that gender does not have a significant effect on leaving the site. Coefficients of the network indicators suggest that having more friends and having more communities are associated with staying longer on the site, but a more clustered local network is related to a higher likelihood of leaving (cf. Lörincz et al., 2019). 
Table 4. Discrete-time survival models on leaving the OSN (coefficients)

\begin{tabular}{|c|c|c|c|c|}
\hline & \multicolumn{4}{|c|}{ Dependent variable: leaving the OSN } \\
\hline & Model 1 & Model 2 & Model 3 & Model 4 \\
\hline User age & $\begin{array}{l}-0.0103 * * * \\
(0.00122)\end{array}$ & $\begin{array}{l}-0.0111^{* * *} \\
(0.00125)\end{array}$ & $\begin{array}{l}-0.0119 * * * \\
(0.00124)\end{array}$ & $\begin{array}{l}-0.0179^{* * *} \\
(0.00131)\end{array}$ \\
\hline User gender & $\begin{array}{l}-0.00482 \\
(0.0323)\end{array}$ & $\begin{array}{l}-0.00637 \\
(0.0332)\end{array}$ & $\begin{array}{l}-0.0182 \\
(0.0333)\end{array}$ & $\begin{array}{l}0.00160 \\
(0.0436)\end{array}$ \\
\hline $\mathrm{N}$ of friends $(100)$ & $\begin{array}{l}-0.281 * * * \\
(0.0128)\end{array}$ & $\begin{array}{l}-0.209^{* * *} \\
(0.0125)\end{array}$ & $\begin{array}{l}-0.259^{* * * *} \\
(0.0132)\end{array}$ & $\begin{array}{l}-0.252 * * * \\
(0.0132)\end{array}$ \\
\hline $\mathrm{N}$ of communities & $\begin{array}{l}-0.0741^{* * *} \\
(0.0155)\end{array}$ & $\begin{array}{l}-0.100^{* * * *} \\
(0.0155)\end{array}$ & $\begin{array}{l}-0.0743 * * * \\
(0.0158)\end{array}$ & $\begin{array}{l}-0.0693^{* * *} \\
(0.0157)\end{array}$ \\
\hline Local clustering & $\begin{array}{l}1.373^{* * *} \\
(0.219)\end{array}$ & $\begin{array}{l}3.860^{* * *} \\
(0.187)\end{array}$ & $\begin{array}{l}1.531 * * * \\
(0.264)\end{array}$ & $\begin{array}{l}1.436^{* * *} \\
(0.266)\end{array}$ \\
\hline Modularity & $\begin{array}{l}-2.780^{* * *} \\
(0.170)\end{array}$ & & $\begin{array}{l}-2.424 * * * \\
(0.185)\end{array}$ & $\begin{array}{l}-2.409^{* * *} \\
(0.186)\end{array}$ \\
\hline Community dissimilarities & & & & \\
\hline Age & & $\begin{array}{l}0.0392^{* * *} \\
(0.00444)\end{array}$ & $\begin{array}{l}0.0316^{* * *} \\
(0.00455)\end{array}$ & $\begin{array}{l}0.00274 \\
(0.00526)\end{array}$ \\
\hline Distance $(100 \mathrm{~km})$ & & $\begin{array}{l}-0.132 * * * \\
(0.0413)\end{array}$ & $\begin{array}{l}-0.0830^{* *} \\
(0.0417)\end{array}$ & $\begin{array}{l}0.111 \\
(0.0699)\end{array}$ \\
\hline Gender & & $\begin{array}{l}0.711^{* * *} \\
(0.190)\end{array}$ & $\begin{array}{l}0.752 * * * \\
(0.190)\end{array}$ & $\begin{array}{l}0.952 * * * \\
(0.192)\end{array}$ \\
\hline $\begin{array}{l}\text { Ego's distinction from } \\
\text { friends }\end{array}$ & & & & \\
\hline Age & & & & $\begin{array}{l}0.0504 * * * \\
(0.00459)\end{array}$ \\
\hline Distance $(100 \mathrm{~km})$ & & & & $\begin{array}{l}-0.225^{* * * *} \\
(0.0759)\end{array}$ \\
\hline Gender & & & & $\begin{array}{l}-0.0311 \\
(0.168)\end{array}$ \\
\hline Pseudo- $\mathrm{R}^{2}$ & 0.130 & 0.128 & 0.132 & 0.135 \\
\hline Observations & 372,931 & 369,119 & 369,119 & 369,108 \\
\hline
\end{tabular}

Notes: Time is included in nonparametric form. Standard errors in parentheses. *** $\mathrm{p}<0.001,{ }^{* *} \mathrm{p}<0.01,{ }^{*} \mathrm{p}<0.5$

To compare the magnitude of different effects with each other, and across models, we calculated the average marginal effects of our estimates (Table 5). Our estimated marginal effects in Model 4 predict that the baseline probability of leaving $(0.0129$, Table 3$)$ approximately doubles if users have 500 less friends, or they have 19 fewer communities. The 500 friends difference corresponds to twice the interquartile range in the number of friends, so it is an effect of 
moderate value. On the other hand, $99 \%$ of the users have less than 5 communities, so we can conclude that while this relationship is statistically significant, it is quite small in magnitude.

To illustrate the effect of modularity and ease its interpretation, we compare the probability of leaving for users with relatively low and high modularity. Figure 4 presents the effect of modularity using the hazard (Panel A) and survival (Panel B) ratios estimated from our saturated model (Table 4 Model 4). We compare the estimated hazard and survival ratios for high and low modularity users. High modularity represents observations with the highest quartile of modularity (over 0.46 ), and low modularity the lowest quartile (under 0.23 ). It is visible that the hazard rate increases with time, but this increase is much steeper in case of low modularity. Accordingly, as time passes, the probability of survival (remaining on the site) is substantially higher for users with high modularity.

Figure 4. The empirical hazard and survival function of Model 4 for users with high and low modularity. Lines represent mean estimates, shaded areas $95 \%$ confidence intervals. High modularity: over 0.46 ; low modularity: under 0.23 .
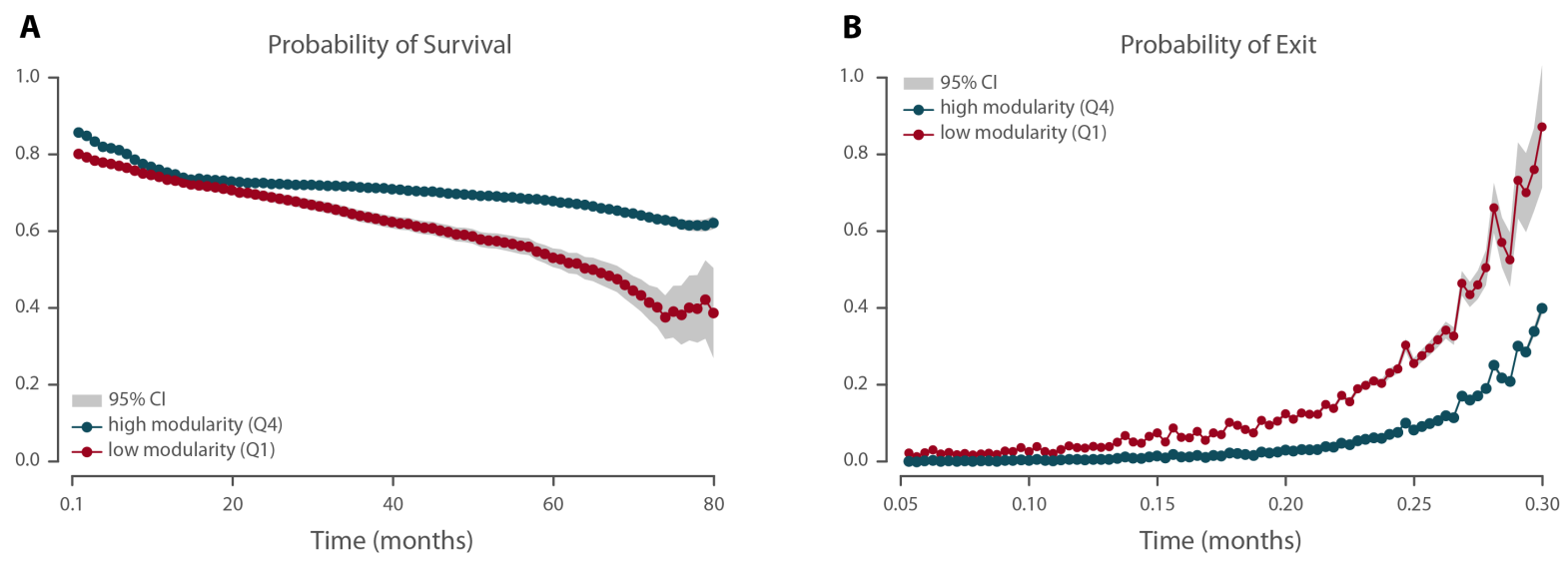
Table 5. Discrete-time survival models on leaving the OSN (average marginal effects)

\begin{tabular}{|c|c|c|c|c|}
\hline & \multicolumn{4}{|c|}{ Dependent variable: leaving the OSN } \\
\hline & Model 1 & Model 2 & Model 3 & Model 4 \\
\hline User age & $\begin{array}{l}-0.000108^{* * *} \\
(1.29 \mathrm{e}-05)\end{array}$ & $\begin{array}{l}-0.000116^{* * *} \\
(1.31 \mathrm{e}-05)\end{array}$ & $\begin{array}{l}-0.000124^{* * *} \\
(1.30 \mathrm{e}-05)\end{array}$ & $\begin{array}{l}-0.000186^{* * *} \\
(1.39 \mathrm{e}-05)\end{array}$ \\
\hline User gender & $\begin{array}{l}-5.04 \mathrm{e}-05 \\
(0.000338)\end{array}$ & $\begin{array}{l}-6.63 \mathrm{e}-05 \\
(0.000346)\end{array}$ & $\begin{array}{l}-0.000189 \\
(0.000346)\end{array}$ & $\begin{array}{l}1.66 \mathrm{e}-05 \\
(0.000453)\end{array}$ \\
\hline $\mathrm{N}$ of friends $(100)$ & $\begin{array}{l}-0.00294 * * * \\
(0.000139)\end{array}$ & $\begin{array}{l}-0.00218^{* * * *} \\
(0.000134)\end{array}$ & $\begin{array}{l}-0.00269 * * * \\
(0.000142)\end{array}$ & $\begin{array}{l}-0.00262 * * * \\
(0.000142)\end{array}$ \\
\hline $\mathrm{N}$ of communities & $\begin{array}{l}-0.000775^{* * * *} \\
(0.000163)\end{array}$ & $\begin{array}{l}-0.00105^{* * * *} \\
(0.000162)\end{array}$ & $\begin{array}{l}-0.000772^{* * * *} \\
(0.000165)\end{array}$ & $\begin{array}{l}-0.000720^{* * * *} \\
(0.000164)\end{array}$ \\
\hline Local clustering & $\begin{array}{l}0.0144 * * * \\
(0.00230)\end{array}$ & $\begin{array}{l}0.0402 * * * \\
(0.00203)\end{array}$ & $\begin{array}{l}0.0159^{* * * *} \\
(0.00276)\end{array}$ & $\begin{array}{l}0.0149 * * * \\
(0.00277)\end{array}$ \\
\hline Modularity & $\begin{array}{l}-0.0291 * * * \\
(0.00182)\end{array}$ & & $\begin{array}{l}-0.0252 * * * \\
(0.00195)\end{array}$ & $\begin{array}{l}-0.0250^{* * *} \\
(0.00197)\end{array}$ \\
\hline $\begin{array}{l}\text { Community } \\
\text { dissimilarities }\end{array}$ & & & & \\
\hline Age & & $\begin{array}{l}0.000409 * * * \\
(4.66 \mathrm{e}-05)\end{array}$ & $\begin{array}{l}0.000329 * * * \\
(4.76 \mathrm{e}-05)\end{array}$ & $\begin{array}{l}2.84 \mathrm{e}-05 \\
(5.47 \mathrm{e}-05)\end{array}$ \\
\hline $\begin{array}{l}\text { Distance } \\
(100 \mathrm{~km})\end{array}$ & & $-0.00138^{* *}$ & $-0.000863^{*}$ & 0.00115 \\
\hline & & $(0.000431)$ & $(0.000433)$ & $(0.000727)$ \\
\hline Gender & & $\begin{array}{l}0.00741 * * * \\
(0.00199)\end{array}$ & $\begin{array}{l}0.00782 * * * \\
(0.00198)\end{array}$ & $\begin{array}{l}0.00989 * * * \\
(0.00200)\end{array}$ \\
\hline $\begin{array}{l}\text { Ego's distinction fi } \\
\text { friends }\end{array}$ & & & & \\
\hline Age & & & & $\begin{array}{l}0.000523 * * * \\
(4.82 \mathrm{e}-05)\end{array}$ \\
\hline $\begin{array}{l}\text { Distance } \\
(100 \mathrm{~km})\end{array}$ & & & & $-2.34 \mathrm{e}-05^{* *}$ \\
\hline Gender & & & & $\begin{array}{l}(7.89 \mathrm{e}-06) \\
-0.000324 \\
(0.00174)\end{array}$ \\
\hline Pseudo- $\mathrm{R}^{2}$ & 0.130 & 0.128 & 0.132 & 0.135 \\
\hline Observations & 372,931 & 369,119 & 369,119 & 369,108 \\
\hline
\end{tabular}

\section{Interactions}

To examine the interactions between modularity and the different community dissimilarity measures, corresponding to $\mathrm{H} 3$, we included interactions to the saturated model (Table 4 Model 
4). The results are shown in Table 6 . We found significant interaction between modularity and community age dissimilarity, modularity and community gender dissimilarity, but not between modularity and geographical dissimilarity.

Table 6. Discrete-time survival models on leaving the OSN with interaction effects

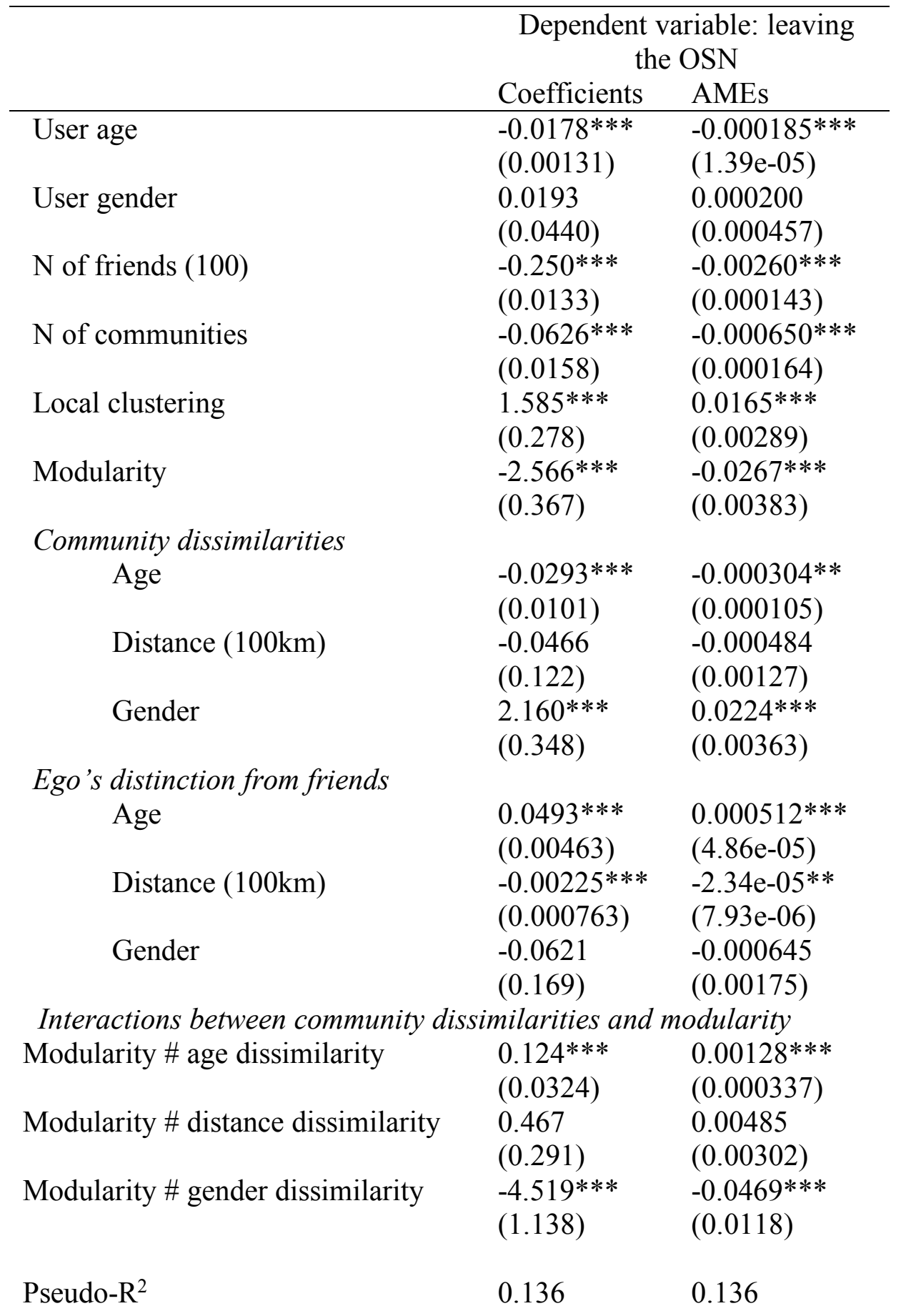


Notes: Time is included in nonparametric form. Standard errors in parentheses. $* * * \mathrm{p}<0.001,{ }^{* *} \mathrm{p}<0.01,{ }^{*} \mathrm{p}<0.05$

We visualize these interactions in respect to the average marginal effects in Figure 5. These indicate that the higher the age dissimilarity is between communities in the ego-network, the stronger the effect of modularity on leaving - which supports H3. To the contrary, the larger the dissimilarity between the gender composition of the communities, the weaker the effect of modularity on leaving. This later result stands in contrast to H3. So highly diverse communities in terms of age increase, while highly diverse communities in terms of gender decrease the estimated effect of modularity on leaving. The results show that there is no general cross-effect of modularity and community dissimilarity, but it depends on the content of dissimilarity measures. It is also apparent that differences in leaving are more prevalent according to modularity, but community dissimilarities play a less important role.

Figure 5. The interaction effect of modularity with age and gender community dissimilarities on leaving the OSN
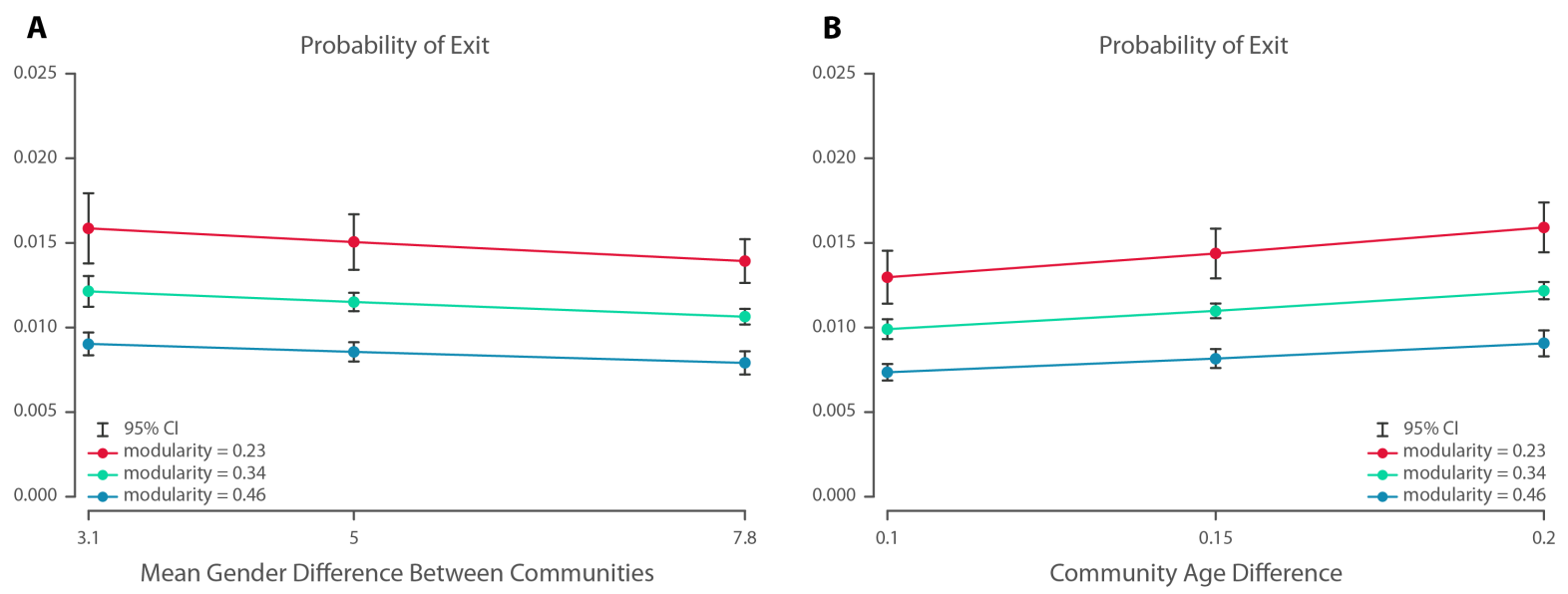


\section{Alternative specification}

To check the robustness of our findings, we ran models with an alternative specification. As logging in to the network is a very low-effort activity, we examined our hypotheses using an alternative measurement of leaving, defining it by the last time of creating a new tie; an act that indicates higher commitment. Thus, we run models with the dependent variable of the date of the user's last tie creation. The results are shown in Table 7 in Appendix A2. In general, the effect sizes of our primary structural variables of interest are larger in these alternate specifications, while the dissimilarity variables had weaker effect sizes. In the alternative full model, the same variables are statistically significant with effects in the same direction as in our primary specification. This strengthens our confidence in our primary results.

\section{Discussion}

If diversity and fragmentation in our online social networks create stress and tension, there is reason to be pessimistic about the future of the largest online social networks such as Facebook, Twitter, Instagram, or TikTok. If, on the other hand, platforms like Facebook can separate the diverse audiences, then we can expect them to last. Understanding these consequences is important not only for the providers of OSNs, but also for researchers wanting to understand online lived experience.

Our investigation found limited evidence for such an effect. Originally, we hypothesized that high fragmentation (modularity) of an ego-network would predict that a user leaves the site earlier due to context collapse (H1). Based on our analysis of a large but now defunct online social network (OSN), we reject this hypothesis. Against our expectations, a wide variety of 
model specifications indicate that users with fragmented ego-networks stay on iWiW longer than those users with more cohesive networks.

We also hypothesized that, next to structural fragmentation, the extent to which communities differ would be an important predictor of leaving iWiW (H2). This hypothesis was supported by our results in the case of gender. Gender dissimilarity between communities raise the likelihood of leaving the network. In the case of age and location dissimilarity between communities, we found no significant effects after including various controls in our model.

For a deeper understanding we examined the interaction of modularity and community dissimilarity on leaving the network (H3). If gender dissimilarity is present in a very fragmented ego-network, its effect is less strong. Having a highly fragmented network, however, strengthens the effect of age dissimilarity of communities on leaving. Thus, H3 is supported if we take age dissimilarities of communities into account and it is rejected if we focus on gender dissimilarities.

Taken these together, the following implications can be drawn. First, being member of different communities, does not seem to be a repulsive factor, but an asset in OSNs. It may suggest that advantages, like social capital associated with bridging positions (Burt, 2005; Jackson, 2019) outweighs the stress associated with context collapse. Additionally, from the three measurement of community dissimilarities the only one, which had significant effect on leaving, was gender. The model, which includes interaction terms suggests, however, that gender only affects leaving among those with a less fragmented network (with low modularity). Instead of context collapse, it seems to be more important, how similar (different) the user is to his or her friends. On the one hand, socio-demographic diversity contributes to access to new ideas and social capital (Borgatti et al., 1998; Aral \& Van Alstyne, 2011). On the other hand, preference of 
communication with similar others is a very strong factor in human networks (McPherson et al., 2001). We see that living far away from friends and/or family members predicts staying on iWiW longer. If someone befriends similar people in different places, we do not expect significant tension, especially in a small, rather homogeneous country like Hungary. Further, the significant positive relationship between geographic diversity in the network and staying on iWiW also supports the interpretation that online social networks are used to manage and maintain social ties, especially if keeping contact with these connections would take more effort otherwise - like in the case of geographically distant friends. On the other hand, we see the preference for similarity with regard to age. That is, people, who have similar-aged connections on iWiW, stayed longer, an evidence of enjoyment associated with homophily of networks. We also see that this effect dominates potential context collapse, that is, how similar ego communities are to each other regarding age.

Our study cannot address every aspect of the tradeoff between diversity and tension in social networks. We miss user information on ethnicity, religious belief, political opinion, interests, and socio-economic status. Recent literature on OSNs highlight how users selfsegregate their activity into echo-chambers along the dimensions that interest them the most such as sport or politics (Del Vicario et al., 2016; Flaxman et al., 2016). Even for the attributes we do observe, there are likely complex social interactions relating to context collapse - for instance between gender and age (cf. Sivak \& Smirnov, 2019) - that our models do not capture.

Another dimension of behavior we cannot observe in our data is whether a user partially withdraws from the site by censoring their profile or limiting their posts. Such strategies seem to be optimal responses to context collapse, especially for individuals who still gain significant 
value from their network. Our alternative specification, predicting the time of a user's last new connection, is an attempt to proxy for a shift from active to passive use of the platform.

Changes in usage patterns of iWiW are likely occurred also because of the appearance of a viable substitute: Facebook. A pragmatic user facing context collapse on iWiW may have adopted a strategy of managing identities on different networks (Boyd, 2014). It is likely that some users who go to new platforms relatively early do not entirely abandon the old ones but use them selectively for some of their social circles. Individuals might try to preserve the benefits of belonging to the current OSN, while rebuilding some of their communities at other sites. Those, who perceive context collapse, might purposefully have a strategy of using different OSNs at the same time. In these cases, different OSNs will be actively used for different communities or for different purposes (e.g., one for expressing political opinions, another to share fashion photos). These conscious users adopt new platforms relatively early, but do not leave the old OSNs (Boyd, 2014). These transitions can be observed when the popularity of an OSN is changing. To study this, a qualitative approach would be needed.

Despite these limitations, our study has been the first to provide a comprehensive empirical account of a serious potential systemic consequence of context collapse: exit from an online social network. Our results are therefore of vital relevance for OSN providers. At the same time, we also provide new illustrative support for the theoretical literature that emphasizes the benefits of ego-network diversity compared to its disadvantages. 


\section{References}

Alba, R. D., \& Kadushin, C. (1976). The Intersection of Social Circles: A New Measure of Social Proximity in Networks. Sociological Methods \& Research, 5(1), 77-102.

Allison, P. D. (2014). Event History and Survival Analysis: Regression for Longitudinal Event Data. SAGE publications.

Alwin, D. F., Felmlee, D.H., \& Kreager, D. A. (Eds.) (2018). Social Networks and the Life Course: Integrating the Development of Human Lives and Social Relational Network. Springer International Publishing.

Aral, S., \& Van Alstyne, M. (2011). The diversity-bandwidth trade-off. American Journal of Sociology, 117(1), 90-171.

Beam M. A., Child, J. T., Hutchens, M. J., \& Hmielowski, J. D. (2018). Context collapse and privacy management: Diversity in Facebook friends increases online news reading and sharing. New Media \& Society, 20(7), 2296-2314.

Binder, J. F., Howes, A., \& Smart, D. (2012). Harmony and tension on social network sites: Side-effects of increasing online interconnectivity. Information, Communication \& Society, 15(9), 1279-1297.

Blondel, V. D., Guillaume, J.-L., Lambiotte, R., \& Lefebvre, E. (2008). Fast unfolding of communities in large networks. Journal of statistical mechanics: theory and experiment, 5(10), P10008.

Borgatti, S. P., Jones, C., \& Everett, M. G. (1998). Network measures of social capital. Connections, 21(2), 27-36.

Boyd, D. M. (2008). Taken out of Context: American Teen Sociality in Networked Publics. ProQuest.

Boyd, D. (2014). It's Complicated: The Social Lives of Networked Teens. Yale University Press. 
Brandtzaeg, P. B., \& Lüders, M. (2018). Time Collapse in Social Media: Extending the Context Collapse. Social Media + Society, 4(1), 1-10.

Brooks, B., Hogan, B., Ellison, N., Lampe, C., \& Vitak, J. (2014). Assessing structural correlates to social capital in Facebook ego networks. Social Networks, 37(3), 1-15.

Burkell, J., \& Fortier, A. (2016). Display and Control in Online Social Spaces: Toward a Typology of Users. New Media and Society, 20(3), 845-861.

Burt, R. S. (1995). Structural Holes. Harvard University Press.

Burt, R. S. (2004). Structural holes and good ideas. American Journal of Sociology, 110(2), 349399.

Burt, R. S. (2005). Brokerage and Closure: An Introduction to Social Capital. Oxford university press.

Costa, E. (2018). Affordances-in-practice: An ethnographic critique of social media logic and context collapse. New Media \& Society, 20(10), 3641-3656.

Cox, D. R. (1972). Regression models and life-tables. Journal of the Royal Statistical Society: Series B (Methodological), 34(2): 187-202.

Davis, J. L., \& Jurgenson, N. (2014). Context collapse: Theorizing context collusions and collisions. Information, Communication \& Society, 17(4), 476-485.

Del Vicario, M., Vivaldo, G., Bessi, A., Zollo, F., Scala, A., Caldarelli, G., \& Quattrociocchi, W. (2016). Echo chambers: Emotional contagion and group polarization on facebook. Scientific reports, 6(37825).

Feld, S. L. (1981). The focused organization of social ties. American Journal of Sociology, 86(5), $1015-1035$.

Fischer, C. S. (1977). Networks and Places: Social Relations in the Urban Setting. Free Press. 
Flaxman, S., Goel, S., \& Rao, J. M. (2016). Filter bubbles, echo chambers, and online news consumption. Public opinion quarterly, 80(S1), 298-320.

Garcia, D., Mavrodiev, P., \& Schweitzer, F. (2013). Social resilience in online communities: The autopsy of friendster. In: COSN'13: Proceedings of the first ACM conference on Online social networks (pp. 39-50). Association for Computer Machinery.

Goffman, E. (1978). The Presentation of Self in Everyday Life. Harmondsworth London.

Granovetter, M. (1973). The strength of weak ties. American Journal of Sociology, 78(6), 13601380.

Hogan, B. (2010). The presentation of self in the age of social media: Distinguishing performances and exhibitions online. Bulletin of Science, Technology \& Society, 30(6), $377-386$.

Hwang, H. S., Shim, J. W., \& Park, S. B. (2019). Why we migrate in the virtual world: factors affecting switching intentions in SNS. Information, Communication \& Society, 22(14), 2127-2137.

Jackson, M. O. (2020). A typology of social capital and associated network measures. Social Choice and Welfare, 54(2-3), 311-336.

Jackson, M. O., Rodriguez-Barraquer, T., \& Tan, X. (2012). Social capital and social quilts: Network patterns of favor exchange. American Economic Review, 102(5), 1857-1897.

Jehn, K. A. (1995). A multimethod examination of the benefits and detriments of intragroup conflict. Administrative science quarterly, 40(2), 256-282.

Kossinets, G., \& Watts, D. J. (2009). Origins of homophily in an evolving social network. American Journal of Sociology, 115(2), 405-450. 
Lazarsfeld, P., \& Merton, R. K. (1954). Friendship as a Social Process: A Substantive and Methodological Analysis. In Berger, M., Abel, T., \& Charles, H. (Eds.), Freedom and Control in Modern Society (pp. 18-66). Van Nostrand.

Lengyel, B., Bokányi, E., Di Clemente, R., Kertész, J., \& González, M. C. (2020). The role of geography in the complex diffusion of innovations. Scientific Reports, 10(15065).

Lengyel, B., Varga, A., Ságvári, B., Jakobi, Á., \& Kertész, J. (2015) Geographies of an online social network. PloS ONE, 10(9), e0137248.

Lin, N. (1999). Building a network theory of social capital. Connections, 22(1), 28-51.

Lőrincz, L., Koltai, J., Győr, A. F., \& Takács, K. (2019). Collapse of an online social network: Burning social capital to create it? Social Networks 57, 43-53.

Marsden, P. V. (1988). Homogeneity in confiding relations. Social networks, 10(1), 57-76.

Marwick, A. E., \& Boyd, D. (2011). I tweet honestly, I tweet passionately: Twitter users, context collapse, and the imagined audience. New Media \& Society, 13(1), 114-133.

Marwick, A. \& Boyd, D. (2014). 'It's just drama': teen perspectives on conflict and aggression in a networked era. Journal of Youth Studies, 17(9), 1187-1204.

McPherson, M., Smith-Lovin, L., \& Cook, J. M. (2001). Birds of a Feather: Homophily in Social Networks. Annual Review of Sociology, 27(1), 415-444.

Milliken, F. J., \& Martins, L. L. (1996). Searching for common threads: Understanding the multiple effects of diversity in organizational groups. Academy of management review, $21(2), 402-433$.

Newman, M. E. J., \& Girvan M. (2004). Finding and evaluating community structure in networks. Physical Review E, 69(2), 026113. 
Ngonmang, B., Viennet, E., \& Tchuente, M. (2012). Churn prediction in a real online social network using local community analysis. In ASONAM '12: Proceedings of the 2012 International Conference on Advances in Social Networks Analysis and Mining (pp. 282288). IEEE Computer Society.

Pelled, L. H., Eisenhardt, K. M., \& Xin, K. R. (1999). Exploring the black box: An analysis of work group diversity, conflict and performance. Administrative science quarterly, 44(1), 1-28.

Simmel, G. (2009). Sociology: Investigations on the Forms of Sociation. Brill. (Original work published 1908)

Sivak, E., \& Smirnov, I. (2019). Parents mention sons more often than daughters on social media. Proceedings of the National Academy of Sciences, 116(6), 2039-2041.

Tian, X. (2016). Network domains in social networking sites: expectations, meanings, and social capital. Information, Communication \& Society, 19(2), 188-202.

Török, J., \& Kertész, J. (2017). Cascading collapse of online social networks. Scientific Reports, $7(1), 16743$.

Uzzi, B. (1997). Social Structure and Competition in Interfirm Networks: The Paradox of Embeddedness. Administrative Science Quarterly, 42(1), 35-67.

Vitak, J. (2012). The impact of context collapse and privacy on social network site disclosures. Journal of Broadcasting \& Electronic Media, 56(4), 451-470.

Vitak, J., Lampe, C., Gray, R., \& Ellison, N. B. (2012). "Why won't you be my Facebook friend?": strategies for managing context collapse in the workplace. In iConference '12: Proceedings of the 2012 iConference (pp. 555-557). Association for Computing Machinery. 
Vitak, J., Blasiola, S., \& Patil, S., \& Litt, E. (2015). Balancing audience and privacy tensions on social network sites: Strategies of highly engaged users. International Journal of Communication, 9(1), 1485-1504.

Wachs, J., Yasseri, T., Lengyel, B., \& Kertész, J. (2019). Social capital predicts corruption risk in towns. Royal Society Open Science 6(4), 182103.

Wesch, M. (2009). Youtube and you: Experiences of self-awareness in the context collapse of the recording webcam. Explorations in Media Ecology, 8(2), 19-34. 